Submission to: Corporate Communications: An International Journal

Third round: implementation of reviewers' suggestions (see attached document)

\title{
Communicating CSR: Practices among Switzerland's top 300 companies
}

Authors: Gregory Birth, Laura Illia, Francesco Lurati, and Alessandra Zamparini

\section{Correspondence Address:}

Francesco Lurati, Institute for Corporate Communication, Faculty of Communication Sciences, University of Lugano, Via G. Buffi 13, 6900 Lugano, Switzerland, Tel. +41 (0)58 6664582 , francesco.lurati@lu.unisi.ch

\begin{abstract}
Purpose - To provide a picture of the practice of Corporate Social Responsibility (CSR) communication among the top 300 companies in Switzerland and to investigate how favorable the cultural context is for this kind of communication.
\end{abstract}

Methodology/approach - The investigation of the top 300 companies in Switzerland was conducted using a written survey that built on previous studies.

Findings: CSR communication in Switzerland appears to be well developed, but still has broad margins for development. Examples are provided on how to improve CSR communication. Such improvements should be relatively easy to implement since Switzerland, it is argued, appears to be open to CSR communication.

Research Limitations/Implications - The investigation considered only the communication objectives toward a limited range of stakeholders, such as clients, shareholders, and employees. The survey was conducted among the top 300 companies in Switzerland; these companies are not necessarily representative of the whole Swiss business community.

Practical implications - The paper describes the elements that should be considered in order to develop an effective CSR communication. These elements are synergies between issues, objectives, and channels; criteria for a credible social report; the exploitation of the potentialities of CSR advertising and the web; and the understanding of the national context where the organization is operating.

Originality/value - This paper focuses on CSR communication, an area that has received limited attention in CSR research. Organizations may find interesting hints on how to develop effective CSR communication.

Paper type - Research paper 


\section{Introduction}

Nowadays it is becoming increasingly important for companies to communicate their Corporate Social Responsibility (CSR) as such activities may influence opinion leaders' behaviors regarding a target organization (APCO, 2004). Furthermore, CSR activities need to be communicated properly in order to counteract the growing skepticism of corporate communication, particularly companies that overstate their social behaviors (Holme and Watts, 2000). In fact, this trend is fueled by global communication that fosters a context in which organizations are more open to external expectations (Elkington, 1998), making public opinion an important gatekeeper of organizational CSR (Esrock and Leichty, 1998).

The potential for exploring CSR communication has led this team of researchers to develop a study focusing on CSR communication practice in Switzerland. The aim of this analysis is to understand how common CSR communication is among the top 300 companies in Switzerland as well as how they communicate CSR. Switzerland's citizens deem the values of universalism and benevolence important (Schwartz, 2003); therefore, it will be interesting to determine how the top 300 companies consider the Swiss context with regard to CSR communication.

The current survey relies on previous studies concerning key elements in CSR communication, such as CSR communication objectives and channels. The discussion of CSR communication objectives will incorporate a large multidisciplinary mix of literature, particularly relying on contributions regarding CSR and customer care (e.g., McWilliams and Siegel, 2001; Dawkins and Lewis, 2003), CSR and employer reputation (Joyner and Payne, 2002; Bauer and Smith, 1996; Turban and Greening, 1996; Mowday, Porter and Steers, 1979) and socially responsible investing (Hockerts and Moir, 2004; Keeler, 2003; Mainelli, 2004). This literature acknowledges the importance of defining CSR communication strategies in terms of stakeholders and, consequently, issues. The discussion of the use of CSR communication channels will refer to research contributions from CSR Europe (2000a, 2000b), Holme and Watts (2000), Ku, Kaid and Pfau (2003), Drumwright (1996), and Esrock and Leichty (1998). Finally, the discussion will examine the cultural context for CSR communication. As some studies have shown (Tixier, 2003), organizations in Anglo-Saxon countries are more likely to communicate social responsible topics than those operating in Latin countries. The present research will define a set of criteria to help understand if the top 300 companies in Switzerland consider the Swiss context as more Anglo-Saxon- or Latin-oriented by analyzing companies' attitudes toward CSR communication. 
The paper is organized into four sections; the first two cover the conceptual framework, while the remaining two the empirical part. The first section will provide a definition of CSR communication, and the second section will address the key elements of effective CSR communication management. The discussion will argue that, in addition to carefully defining objectives and channels, effective CSR communication must also consider the communication's cultural context; the discussion will provide the dimensions used in the empirical investigation. The third section will detail the survey methodology, and the fourth part will present and discuss the main findings.

\section{CSR communication}

The fundamental idea embedded in CSR is that corporations have an obligation to work for social betterment (Frederick, 1978). The same view is shared by the World Business Council for Sustainable Development (WBCSD), which considers CSR management to mean acting responsibly with other stakeholders and ethically toward society (Holme and Watts, 2000). Similarly, Sethi (1975), Carroll (1979), and Andrews (1987) identify four categories of social responsibility: economic, legal, ethical, and discretionary.

Deegan and Gordon (1996), Deegan and Rankin (1999), Brown and Deegan (1998), and Hooghiemstra (2000) apply this conceptual framework to CSR communication, emphasizing that CSR communication aims to provide information that legitimizes an organization's behavior by trying to influence stakeholders' and society's image of the company. Following this definition, it is possible to conclude that CSR communication contributes to a corporation's Corporate Social Disclosure (Zéghal and Ahmed, 1990), which is the dissemination of information to advocate and enhance a corporate image in order to promote customer and community relations and indirectly promote products to customers.

To reach this goal, transparency is crucial (Carroll, 1999). However, as pointed out by Schoenberger (2000), transparency in the field of CSR is a difficult matter. In fact, data in this area cannot easily be verified. Furthermore, communicating CSR means communicating not only about a company's behavior through standards or codes of conduct, but also about very long-term projects whose potential outcomes are difficult to represent. 


\section{Key elements for effective CSR communication}

The intrinsic problems encountered in achieving transparent CSR communication can be overcome by developing an appropriate definition of the communication objectives and channels as well as by understanding the communication context. Much evidence supporting this view has been discussed in recent literature; the following paragraphs will cover the main aspects that will subsequently be investigated in the empirical part of this article.

\section{CSR communication objectives}

Objectives should be defined in line with emerging issues and corresponding stakeholders. The issues normally covered by CSR communication are broad (CSR Europe, 2000b; Esrock and Leichty, 1998; Holme and Watts, 2000) and include mission, vision and values, workplace climate, social dialogue, human rights, community involvement, development of the local economy, environment, market relations, and ethics. Recent literature focuses on the importance of defining clear communication objectives for each stakeholder. Particular attention is paid to three specific types of stakeholders: clients, employees, and shareholders.

Moreover, three types of objectives characterize CSR communication addressed to clients: reputation, product differentiation, and customer loyalty. Social and environmental responsibility is one of the dimensions of the Reputation Quotient developed by Fombrun, Gardberg and Sever (2000), and McWilliams and Siegel (2001) assert that consumers consider socially responsible firms to have a good reputation. The impact of CSR on reputation was confirmed by a recent study conducted by British Telecom (2002); this study found that CSR represents 25 percent of a company's reputation asset. Thus, improving reputation through CSR is an important objective since a good reputation influences consumer satisfaction-i.e. products are considered more reliable and of a higher quality (McWilliams and Siegel, 2001). This affirmation is also supported by a study conducted by the British Institute's Market and Opinion Research International (MORI) (Dawkins and Lewis, 2003). In addition, as APCO's (2004) worldwide study revealed, CSR communication supports the ability to market a product, allowing for better differentiation and premium prices. Thus, product differentiation is an important objective addressing clients. Finally, companies use CSR communication to enhance customer loyalty. As Jacob and Kyner (1973) and Keller (1993) emphasize, socially responsible organizations attract more customer loyalty since such organizations relate to clients with greater respect, monitor client satisfaction by proving timely responses to their claims, and have high standards of security as well as transparent communication about their products. 
Meanwhile, companies promote CSR communication among employees mainly through internal communication (Dawkins and Lewis, 2003), pursuing four main objectives. The first objective aims to create publicity and a good reputation through word of mouth. The MORI study (Dawkins and Lewis, 2003) found that employees represent a powerful channel through which to convey positive messages about the company; 85 percent of employees are more likely to initiate spontaneous word-of-mouth promotion when they are involved in the CSR initiatives of the company, while 65 percent are more likely to do so when they are informed about such corporate initiatives. The second objective of CSR communication with regard to employees is to increase employees' satisfaction and commitment. Previous studies have demonstrated a relationship between employees' loyalty and their company's CSR (Bevan and Wilmott, 2002). Indeed, employees working in an ethical and socially responsible company are more committed to the company (Joyner and Payne, 2002) since work activities become more enjoyable (Mowday et al., 1979). This objective is linked to the first one since higher satisfaction and commitment resulting from CSR engenders publicity through word of mouth. The third objective discussed in the literature with regard to employees is the ability of CSR communication to enhance the appeal of the company as a future employer. Potential employees are more attracted by employers with ethical integrity and socially responsible behavior (Joyner and Payne, 2002; Bevan, Isles and Emery, 2004; Keeler, 2003). Finally, CSR communication can reduce employee turnover. When employees consider their organization to be socially responsible, they are less likely to leave (Bevan and Wilmott, 2002) since they believe they have similar values to those of the organization for which they work (Maignan, Ferrel and Hult, 1999).

CSR communication objectives involving shareholders support the overall financial communication objectives - i.e. achieving and maintaining a favorable climate for the financial situation of the company, increasing and maintaining share price, and increasing the volume of share trading. The first objective aims at increasing the awareness that the company represents an actual opportunity for investing in a socially responsible way. Investors make decisions by looking at how corporations shape their behavior in terms of response to multiple stakeholders' expectations (Hockerts and Moir, 2004). Socially responsible investing (SRI) has grown substantially in the last years, persuading companies to present themselves as socially responsible (Keeler, 2003). The second communication objective with regard to shareholders is communicating the tangible advantages of the company's CSR strategy. According to Mainelli 
(2004), socially responsible organizations produce more profit than non-socially responsible organizations and show less volatility in their earnings due to the reduced activist action.

\section{Channels of CSR communication}

According to CSR Europe (2000a, 2000b), companies use a wide range of channels for CSR communication, including social reports, thematic reports, codes of conduct, websites, stakeholder consultations, internal channels, prizes and events, cause-related marketing, product packaging, interventions in the press and on TV, and points of sale. However, three channels in particular-social reports, websites, and advertising — seem to play the prominent role, as shown in several recent studies.

Social reports are the main channel for communicating "the social and environmental effect of organizations' economic actions to particular interest groups within society and to society at large" (Gray, Owen and Adams, 1996). Throughout the 1990s in Western Europe, 68 percent of big companies produced social reports (CSR Europe, 2003). However, to a certain extent, stakeholders were dissatisfied with this type of channel since companies were often accused of writing arbitrary reports not based on quantifiable data (Crook, 2005). In response to this situation, companies have increasingly relied on international reporting standards and third-party certification for their social reports.

Although reporting on social actions is voluntary, some European governments are implementing mandatory laws on reporting (e.g., France and Spain), while in other countries the adoption of international reporting standards is growing fast, even though no mandatory regulations exist in the EU at the moment (Tschopp, 2005). Three categories of standards exist. The first provides guidelines on the structure and contents of social reports; one example is the Global Reporting Initiative (GRI), which is being adopted by an increasing number of companies. The second category comprises the certification standards that address specific social issues, such as SA8000, which deals with workers' rights, and ISO 14000, which deals with environmental management issues. Finally, the auditing and stakeholder involvement standards represent the third pillar of the CSR standards system; AA1000 has grown increasingly popular as the reference framework in this field as it provides guidelines on how to engage stakeholders effectively in CSR management processes. This assurance standard is of particular importance when it comes to corporate credibility. In fact, it is largely acknowledged that social reports without actual stakeholders' involvement fail to meet the expectations of transparency and accountability (Dando and Swift, 2003; Adams and Evans, 2004). 
According to Tschopp (2005), a social report that is not regulated by standards or external guidelines risks becoming merely a marketing tool, not meeting the requirements of stakeholders such as investors, lobbyists, and NGOs. "The best way to convince stakeholders that a company is as good as its corporate citizenship report is to have the report audited by an independent consultant” (Keeler, 2003). APCO's (2004) Global CSR Study of opinion leaders also found that 90 percent of those interviewed think that third-party independent certification gives credibility to the social report. Standards like SA8000 and ISO 14000 can be implemented only through thirdparty certification. Other standards, such as GRI and AA1000, are constantly developing services aimed at providing external certification regarding the appropriate application of these standards.

The web also has the potential to play a prominent role in CSR, particularly as a means to influence agenda (Esrock and Leichty, 1998). Ku et al. (2003) provided evidence of a convergence between websites' agendas and the public agenda, revealing a possible relationship between them as well as supporting Esrock and Leichty's (1998) thesis.

Finally, advertising has been abundantly used in the last decades to communicate social responsibility themes, but the effectiveness has been quite controversial. Drumwright (1996) has pointed out several shortfalls of CSR advertising. On the one hand, this type of campaign is often criticized by the public: companies are actually accused of making use of social problems for business purposes. On the other hand, such campaigns often have to face management distrust of CSR advertising outcomes and processes. These campaigns are often accused of not having short-term economic results, although they clearly have long-term objectives; moreover management considers the creative process to be too long and complex, consequently resulting in the need for too much time for development. Finally management believes the measurement of results to be problematic.

\section{Cultural context of CSR communication}

Understanding the context is also an important element in effectively managing CSR communication. Organizations from different countries have diverse perspectives on the importance of being perceived as socially responsible by the public (Maignan and Ralston, 2002). The approach mostly depends on the cultural context in which an organization operates as well as the demonstrated relationship between culture and social disclosures (Haniffa and Cooke, 2005). According to Tixier (2003), organizations have two alternatives for communicating CSR: total discretion or "high-risk" communication. The former is typical in Latin countries, while the latter 
is typical in Anglo-Saxon countries. Interpreting Tixier's discussion on this dichotomy, three elements emerge to help determine if an organization operates in a Latin or Anglo-Saxon context:

- Integration of CSR into the corporate strategy: In a Latin context, a company separates CSR activities from business and considers them to be discreet and disinterested generosity; in an Anglo-Saxon context, a company integrates CSR activities within its strategy, considering them a win-win approach.

- Media context and companies' reaction to it: In a Latin context, the media are suspicious of companies that communicate CSR while companies consequently fear media's criticism; in an Anglo-Saxon context, the media tend to support businesses that communicate CSR and, consequently, companies do not fear their criticism.

- Management tendency to take risks: In a Latin context, management thinks that it is too risky to build a corporate image on CSR activities because of the boomerang effect emerging as soon as a problem arises; in an Anglo-Saxon context, management thinks that CSR can have a positive effect on corporate image since full disclosure is an important part of CSR strategy when facing problems as well.

Tixier (2003) provides an example of the opposition of the two cultures. The silent approach is typical in France, where 61 percent of organizations with a turnover of over 20 billion French francs decide not to communicate CSR (UDA, 2001, as cited in Tixier, 2003). The cultural context in France constitutes an obstacle to communication of CSR. On one hand, managers do not want to take risks, as CSR is not considered a value for the corporate strategy as a whole; on the other hand, the media and public opinion are culturally reluctant to recognize the positive aspects of social actions taken by companies. In the Anglo-Saxon context, the "high-risk" approach is much more diffuse. Here "social corporate responsibility generates value, just as the other policies of Anglo-Saxon companies do" (Tixier, 2003), and socially responsible activities carried out by companies are seen by the media as a benefit for both organizations and society. Furthermore, even if the media watch over organizations' behavior, there is a higher tendency to take risks on the part of the management.

Other authors who have investigated CSR in countries categorized as Anglo-Saxon by Tixier have indirectly confirmed her conclusions. For example, Dawkins and Lewis (2003) assert that it is worth taking the risk because, even if a lack of esteem for companies' actions exists among stakeholders, it is also true that organizations acting responsibly have a better chance of winning the trust of the public, which is becoming more and more demanding about information on CSR. Data collected by MORI support this statement; in fact 74 percent of the British public declares 
that having more information on companies' social, environmental and ethical behavior can influence their purchasing decisions (Dawkins, 2004).

\section{Methodology}

In our research, unlike previous studies (e.g., Zéghal and Ahmed, 1990; Williams and Pei, 1999; Snider, Hill and Martin, 2003), the methodology did not involve content analysis, but a survey. This approach is justified not only by the necessity to investigate issues, channels, and stakeholders addressed by the CSR communication, but also by the need to explore the communication objectives that corporations plan for CSR communication and the communication context for the CSR communication.

\section{Participants}

The participants included the 300 companies cited in the PME Magazine (2004) article. A fairly large proportion of the participants experienced a turnover of more than 5,000 million CHF (29 percent of total respondents and 37 percent of respondents communicating CSR); the participating companies from the second largest group had a turnover from 1,000 to 2,499 million CHF (26 percent of total respondents and 27 percent of respondents communicating CSR). The rest of the sample is composed of companies with a turnover of less than 1,000 million CHF, companies with a turnover between 3,000 and 4,999 million CHF, or companies that did not reveal their annual turnover.

\section{Survey method and type of analysis}

The questionnaire included 25 questions: 1 preliminary question to identify which companies carry out CSR communication, 7 questions regarding communicating CSR issues and channels, 8 questions regarding strategic stakeholder CSR communication, 2 questions regarding the Swiss context, and the remaining 7 questions ask for company-related information. The questions referring to the Swiss context measure the Latin or Anglo-Saxon orientation using a semantic scale from -3 to 3 . All other questions are either dummy questions or qualify the level of CSR communication.

\section{Answer rate}

The questionnaires were completed primarily by the head of communications ( 40 percent of total respondents and 44 percent of respondents that communicate CSR); many were completed by a person with a specific CSR role (14 percent of both the total and of the respondents 
communicating CSR). Other questionnaires were completed by professional figures, including the head of investor relations, the head of human resources, the head of public relations, or the CEO (table 1).

Table 1

Professional figures responding to the survey

\begin{tabular}{lcc}
\hline Professional figure & Respondents (\%) & Respondents Communicating CSR (\%) \\
\hline External agency & $5 \%$ & $5 \%$ \\
Specific CSR role & $14 \%$ & $14 \%$ \\
CEO & $6 \%$ & $8 \%$ \\
Head of IR & $3 \%$ & $2 \%$ \\
Head of HR & $6 \%$ & $8 \%$ \\
Head of PR & $3 \%$ & $4 \%$ \\
Head of Communication & $40 \%$ & $44 \%$ \\
Other & $6 \%$ & $6 \%$ \\
Not available & $17 \%$ & $9 \%$ \\
\hline
\end{tabular}

The survey response rate was 23 percent-i.e., 70 out of 300 companies. A minor bias was found in the population in that a small proportion (4 percent of total population) of the top 300 companies was not represented-i.e., media retail and watch companies (table 2). Out of the 70 companies, 52 (74 percent) communicate CSR, whereas 18 (26 percent) do not. In particular, 62 percent of the respondents communicating CSR are multinational companies-i.e., producing or selling their products on more than one continent.

\section{Results and discussion}

Survey data are mostly reported in frequency terms and refer only to companies that actually communicate CSR. Only data related to the cultural context will be discussed, referring, respectively, to the companies that communicate CSR and those that do not. When appropriate and statistically relevant, data are also discussed in terms of specific groups of companies or communication practice. 
Table 2

Response rates

\begin{tabular}{|c|c|c|c|}
\hline Industry & Population & Respondents (\%) & Respondents communicating CSR (\%) \\
\hline Bank & 55 & $31 \%$ & $27 \%$ \\
\hline Food & 20 & $25 \%$ & $20 \%$ \\
\hline Electronics & 13 & $23 \%$ & $23 \%$ \\
\hline Transport/Traffic & 12 & $33 \%$ & $33 \%$ \\
\hline Insurance & 11 & $36 \%$ & $0 \%$ \\
\hline Chemical & 10 & $60 \%$ & $50 \%$ \\
\hline Energy & 10 & $20 \%$ & $0 \%$ \\
\hline Car & 9 & $22 \%$ & $11 \%$ \\
\hline Retail & 9 & $22 \%$ & $0 \%$ \\
\hline Textile & 6 & $33 \%$ & $17 \%$ \\
\hline Watch/Clock & 5 & $0 \%$ & $0 \%$ \\
\hline Tourism & 4 & $50 \%$ & $25 \%$ \\
\hline Wholesale & 3 & $0 \%$ & $0 \%$ \\
\hline Metalworking & 3 & $67 \%$ & $67 \%$ \\
\hline Telecommunications & 3 & $100 \%$ & $100 \%$ \\
\hline Media & 3 & $0 \%$ & $0 \%$ \\
\hline Furniture & 2 & $50 \%$ & $50 \%$ \\
\hline Other & 56 & $27 \%$ & $21 \%$ \\
\hline TOTAL & 300 & $23 \%$ & $17 \%$ \\
\hline
\end{tabular}

The results emerging from the analysis can be grouped into two main conclusions. First, CSR communication is a common practice among top companies in Switzerland; however, the practice still has considerable room for improvement. Second, Switzerland emerges as a favorable context for CSR communication, which is good news for a practice that can be further developed.

\section{CSR communication in Switzerland}

According to the survey results, CSR communication is carried out by two thirds of the respondents. A great majority of them understand the importance of communicating with specific stakeholders, particularly internal and financial stakeholders. However, the practice could be 
improved, especially as it relates to planning, reporting standards, and using specific communication channels (e.g., advertising, mass media, and packaging).

\section{Internal communication of CSR for both internal and external publics}

Based on the survey results, 98 percent of the respondents communicate CSR to their employees. While 84 percent consider their first CSR communication objective to be "to increase employees' satisfaction and commitment," another 57 percent consider it to be "to create publicity and a good reputation through word-of-mouth advertising." In addition, 49 percent believe the objectives include "increasing the appeal of the company as a future employer," while only 10 percent consider such communication for "decreasing employee turnover." Based on these data, the top 300 companies in Switzerland seem to consider the potential of internal communication as a means to reach external publics indirectly as well.

\section{Improving a dialogue with shareholders and the financial community}

Among respondents communicating with shareholders (83 percent $)^{[1]}, 70$ percent aim "to increase the awareness of socially responsible investing (SRI) in the company," 21 percent aim "to communicate the tangible advantages of the company's CSR strategy," 7 percent communicate without a clear objective, and the remaining 2 percent have other objectives. The low percentage of companies that communicate tangible advantages could be due to the inherent difficulty in measuring the outcome of CSR projects and subsequently reporting on them.

SRI is growing in importance in Switzerland. Indeed, 44 percent of the respondents that communicate CSR and that are listed on the stock exchange indicated that they sometimes receive a request for information from the financial community about their CSR; 19 percent receive such requests very often. Moreover, the importance of SRI is revealed by the fact that 70 percent of respondents - both those listed and not listed on the stock exchange-indicated think that the dialogue between their company and shareholders on CSR issues has somewhat improved; 25 percent indicated that it has definitely improved. The importance that the companies active in Switzerland attribute to shareholder communication suggests that they are aware of the added value they might gain in leveraging SRI investments. 
"Hot" issues and synergies

The top 300 companies in Switzerland communicate on a broad variety of social issues; 30 percent of the respondents communicating CSR address all the issues considered, and 98 percent consider at least four issues. The most communicated issues are classical subjects, such as mission, vision, and values as well as environment, immediately followed by ethics, workplace climate, and community involvement. Moreover, multinational companies operating in Switzerland communicate intensively on specific issues, such as human rights, development of local economy, ethics, and community involvement. These data reflect a mixed picture. On the one hand, it appears that top companies could be more focused on their CSR communication, improving their chance to be effective. On the other hand, their apparent fragmentation may be mitigated by the fact that the most related issues are generally considered "hot" issues (Schwartz and Gibb, 1999; Klein, 1998; Elkington, 1998).

Regarding channels, it seems again that the top 300 companies in Switzerland rely on a wide range of alternative channels, although with some differences. In fact, the most used channels are internal ones (77 percent of total respondents) while the least used (less than 50 percent of the respondents) are the press, TV, prizes, events, packaging, reports, cause-related marketing, and points of sale. Although the use of such a diversified number of channels suggests a more selective approach to channels would be better, the data partially attenuate this concern. In fact, it seems that specific channels are used for specific issues, suggesting that synergies between the two are exploited. External issues are communicated through external channels, whereas internal issues are conveyed through internal channels (refer to Table 3).

Although the proportion of companies drawing social reports can be considered high, only a minority complies with international reporting standards. According to the data, 67 percent of respondents communicate CSR through social reports. This figure is in line with European figures (68 percent, according to CSR Europe, 2003). It seems that companies not producing a social report are those with low revenue ${ }^{[2]}$.

In addition, 23 percent are certified by ISO 14000, a certification in the environmental area-an issue largely communicated by companies in Switzerland. However, these data are not relevant communication-wise. In fact ISO 14000 certifies activities, not communication. In this regards, the data concerning the compliance to the Global Reporting Initiative (GRI) standard is more significant; only 24 percent of the respondents indicated using GRI standards, revealing a great potential for improving the effectiveness of social reporting in Switzerland. 
The web: A well-exploited channel

The potential of the web for communicating CSR seems to be well exploited since respondents included online communication in most elements Esrock and Leichty (1998) consider the web crucial for having an active role in influencing agenda. Fifty percent of the respondents' websites contain editorials, 58 percent report comments, and 15 percent include third-party opinions. In addition, 65 percent state positions. Finally, 75 percent of company websites contain at least one of these elements; 56 percent contain three of them.

\section{Advertising: A problematic channel}

Forty-four percent of the respondents use advertising to communicate social responsibility; a majority of them (64 percent) acknowledges that this is a difficult process, as argued by Drumwright (1996). The main difficulties declared by respondents implementing CSR advertising campaigns are the longer and more complex creative process (35 percent), the evaluation of results (30 percent), and criticism of the public (21 percent). In addition, 4 percent declared that campaigns were blamed for not achieving short-term results.

These problems are also felt by the firms that do not use advertising to communicate CSR. In fact, they justify their decision to not use advertising with the difficulties in evaluating the results of the campaigns (27 percent), the complexity and the length of the creative process (14 percent), and the public criticism toward this type of campaign (10 percent).

\section{CSR communication to clients: Reality does not correspond to intention}

The top 300 companies in Switzerland are aware of the importance of communicating CSR to clients: 81 percent communicating CSR direct their communication to customers. Furthermore, 62 percent consider their first objective to be "to increase customer loyalty through CSR," while 95 percent consider it to be "to improve their reputation through CSR." This focus on clients reflects the Swiss consumers' profile. In fact, as shown by CSR Europe (2000a), 31 percent of Swiss consumers consider companies' socially responsible behavior in purchasing decisions; 51 percent have the habits of a typical CSR activist. 
Table 3

Issues communicated through the most used channels

\begin{tabular}{lll}
\hline Channel & Issue & Respondents CSR \\
\hline \multirow{3}{*}{ Internal communication } & Mission, vision, values & $93 \%$ \\
& Workplace climate & $83 \%$ \\
\hline \multirow{2}{*}{ Web } & Social dialogue & $65 \%$ \\
\hline \multirow{3}{*}{ Social report } & Mission, vision, values & $92 \%$ \\
& Environment & $86 \%$ \\
\hline \multirow{2}{*}{ Codes of conduct } & Environment & $94 \%$ \\
& Mission, vision, values & $88 \%$ \\
\hline \multirow{3}{*}{ Stakeholder consultation } & Community involvement & $82 \%$ \\
\hline & Ethics & $88 \%$ \\
& Mission, vision, values & $79 \%$ \\
\hline
\end{tabular}

However, despite the high orientation of CSR communication toward clients and the specific communication objectives, the emphasis on client-oriented channels is limited. With the exception of the web, all other channels easily accessible to clients (e.g., advertising, product packaging, mass media) score low in the overall CSR communication effort (well below 50 percent). This finding does not come as a surprise; in fact, according to CSR Europe (2000a), 62 percent of Swiss consumers believe that the corporate world does not pay enough attention to CSR issues.

\section{An Anglo-Saxon attitude toward CSR communication}

The attitude of the top 300 companies in Switzerland toward CSR communication can be described as Anglo-Saxon. In fact, all six indicators used to measure the cultural context (refer to Graph 1) point toward the Anglo-Saxon context. Respondents perceive CSR communication as a win-win approach that is instrumental for building corporate image. They consider it an integral part of corporate strategy. These three indicators clearly confirm the Anglo-Saxon context, which is also supported by the fact that respondents believe that communicating CSR is not risky. The 
attitude toward the media, however, although still indicating a slight propensity for an AngloSaxon culture, is close to being ambiguous. In fact, to a certain extent, the top 300 companies in Switzerland fear the media's judgment when using CSR for business purposes and consider them suspicious of corporate social communication. This trait has been identified in a previous study by Westhues and Einwiller (2006).

\section{Take in Figure 1}

Therefore, although clearly Anglo-Saxon, the CSR communication culture among the top 300 companies in Switzerland reveals potential ambiguity. This becomes more apparent when considering the data concerning companies that do not communicate CSR. In fact, companies communicating CSR have a significantly more Anglo-Saxon attitude than those that do not. This is true for all dimensions except for suspiciousness of the media (see Pearson chi square values in Fig. 1).

\section{Conclusions}

CSR communication is a well-established practice among top companies in Switzerland. Its future rests on a solid basis. In fact, top companies are characterized by a predominantly AngloSaxon approach that is active and positive.

This study has shown how these companies can further improve their efforts in communicating CSR. Three main areas of improvement have been identified. First, companies can gain from a

more focused selection of the social issues to be communicated. Second, a major margin of improvement can occur by handling key publics, such as customers, shareholders, and the financial community - particularly by investing in the specific channels to reach them. Finally, top companies in Switzerland may benefit from adopting international reporting standards.

This investigation has also shown the importance of understanding the cultural determinants of CSR. In this regard, more research is certainly required, especially to better understand differences in behaviors concerning CSR communication that may arise in multicultural contexts, a relevant aspect in the European context, and for multinational companies operating in different cultural environments. 


\section{References}

Adams, C.A. and Evans, R. (2004), "Accountability, Completeness, Credibility and the Audit Expectations Gap", The Journal of Corporate Citizenship, Vol. 14, pp. 97-115.

Andrews, K. R. (1987), The Concept of Corporate Strategy, McGraw-Hill, New York, NY.

APCO (2004), Global CSR Study, Communicating CSR: Talking to People who Listen, www.apcoworldwide.com.

Bauer T. N. and Aiman-Smith L. (1996), "Green career choices: The influence of ecological stance on recruiting", Journal of Business and Society, Vol. 10 No. 4, pp. 445-458.

Bevan, S. and Wilmott, M. (2002), The Ethical Employee, The Work Future Foundation/The Future Foundation, London, England.

Bevan, S., Isles, N., Emery, P., and Hoskins, T. (2004), Achieving High Performance-CSR at the Heart of the Business, The Work Foundation, London, England.

British Telecom (2002), Enlightened values, www.bt.com/betterworld.

Brown, N. and Deegan, C. (1998), "The public disclosure of environmental performance information-A dual test of media agenda setting theory and legitimacy theory", Accounting and Business Research, Vol. 29 No. 1, pp. 21-41.

Carroll, A. B. (1979), "A Three-Dimensional Conceptual Model of Corporate Performance", Academy of Management Review, Vol. 4 No. 4, pp. 497-505.

Carroll, A. B. (1999), "Corporate Social Responsibility. Evolution of a Definitional Construct", Business and Society, Vol. 38 No. 3, pp. 268-296.

Crook, C. (2005), "The Good Company. A survey of corporate social responsibility", The Economist, January 22, p. 54.

CSR Europe (2000a), The first ever European survey of consumers' attitude on corporate social responsibility, CSR Europe Publications, Brussels, Belgium.

CSR Europe (2000b), Communicating Corporate Social Responsibility, CSR Europe Publications, Brussels, Belgium.

CSR Europe (2003), Investing in responsible business: The 2003 survey of European fund managers, financial analysts and investor relations officers, CSR Europe Publications, Brussels, Belgium.

Dando, N. and Swift, T. (2003), "Transparency and Assurance: Minding the Credibility Gap", Journal of Business Ethics, Vol. 44 No. 2/3, pp. 195-200.

Dawkins, J. (2004), "Corporate Responsibility: The communication challenge", Journal of Communication Management, Vol. 9 No. 2, pp. 108-119.

Dawkins, J. and Lewis, S. (2003), "CSR in stakeholder expectations: and their implication for company strategy", Journal of Business Ethics, Vol. 44, pp. 185-193.

Deegan, C. and Gordon, B. (1996), "A study of the environmental disclosure practices of Australian corporations", The Accounting Review, Vol. 26 No. 3, pp. 187-199.

Deegan, C. and Rankin, M. (1999), "The environmental reporting expectations gap: Australian evidence", The British Accounting Review, Vol. 31 No. 3, pp. 313-346. 
Drumwright, M. E. (1996), "Company Advertising With a Social Dimension: The Role of Noneconomic Criteria”, Journal of Marketing, Vol. 60 No. 4, pp. 71-86.

Elkington, J. (1998), Cannibals with forks, Capstone, Oxford, England.

Esrock, S. and Leichty, G. (1998), "Social Responsibility and Web Pages: Self Presentation or Agenda Setting?”, Public Relation Review, Vol. 24 No. 3, pp. 305-319.

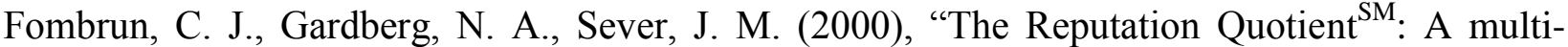
stakeholder measure of corporate reputation", The Journal of Brand Management, Vol. 7 No. 4, pp. 241-255.

Frederick, W. C. (1978), "From CSR1 to CSR2: The maturing of business-and-society thought", Business and Society, Vol. 33 No. 2, pp. 150-164.

Göbbels, M. (2003), "AA1000 and SA8000 compared: A systematic comparison of contemporary accountability standards", Managerial Auditing Journal, Vol. 18 No. 1, pp. 538.

Gray, R., Owen, D., and Adams, C. (1996), Accounting and Accountability: Changes and Challenges in Corporate Social and Environmental Reporting, Prentice Hall Europe, London, England.

Haniffa, R. M. and Cooke, T. E. (2005), "The impact of culture and governance on corporate social reporting", Journal of Accounting and Public Policy, Vol. 24, pp. 391-430.

Hockerts, K. and Moir, L. (2004), "Communicating Corporate Responsibility to Investors: The Changing Role of the Investor Relation Function", Journal of Business Ethics, Vol. 52, pp. $85-98$

Holme, L. and Watts, P. (2000), Corporate social responsibility: Making good business sense, World Business Council for Business Development, Conches-Geneva, Switzerland.

Hooghiemstra, R. (2000), "Corporate Communication and Impression Management-New Perspectives Why Companies Engage in Corporate Social Reporting", Journal of Business Ethics, Vol. 27, pp. 55-68.

Jacob, J. and Kyner, D. B. (1973), “Brand Loyalty versus Repeat Purchase Behaviour”, Journal of Marketing Research, Vol. 10, pp. 1-9.

Joyner, B. and Payne, D. (2002), "Evolution and Implementation: A Study of Values, Business, Ethics and Corporate Social Responsibility”, Journal of Business Ethics, Vol. 41, pp. 297311.

Keeler, D. (2003), "Shaping up”, Global Finance, Vol. 17, pp. 18-22.

Keller, K. L. (1993), “Conceptualizing, Measuring and Managing Customer Based Brand Equity", Journal of Marketing, Vol. 57 No. 1, pp. 1-22.

Klein, N. (1998), No Logo, HarperCollins Publications, London, England.

Ku, G., Kaid, L., and Pfau, M. (2003), "The Impact of Web Site Campaigns on Traditional News Media and Public Information Processing", Journalism and Mass Communication Quarterly, Vol. 80, pp. 528-547.

Maignan, I., Ferrel, O. C., and Hult, G. T. M. (1999), "Corporate Citizenship: Cultural Antecedents and Business Benefits”, Academy of Marketing Science, Vol. 27 No. 4, pp. 455469. 
Maignan, I. and Ralston, D. A. (2002), "Corporate Social Responsibility in Europe and the U.S.: Insights from Businesses' Self-presentations”, Journal of International Business Studies, Vol. 33 No. 3, pp. 497-514.

Mainelli, M. (2004), "Ethical volatility: how CSR ratings and returns might be changing the world of risk", Balance Sheet, Vol. 12 No. 1, pp. 42-45.

McWilliams, A. and Siegel, A. D (2001), "Corporate Social Responsibility: A Theory of the Firm Perspective", Academy of Management Review, Vol. 26 No. 1, pp. 117-127.

Mowday, R., Porter, L., and Steers, S. (1979), "The Measurement of Organizational Commitment", Journal of Vocational Behaviour, Vol. 14, pp. 224-247.

PME Magazine (2004), Top 2004: les plus grandes entreprises en suisse.

Schoenberger, K. (2000), Levi's Children. Coming to Terms with Human Rights in the Global Marketplace, Grove Press, New York, NY.

Schwartz, S. (2003), "Basic Values in Europe, The Hebrew University of Jerusalem", ESS Launch Conference, Brussels, Belgium.

Schwartz, P. and Gibb, B. (1999), When good companies do bad things, John Wiley and Sons, New York, NY.

Sethi, S. P. (1975), "Dimensions of Corporate Social Responsibility", California Management Review, Vol. 17 No. 3, pp. 58-64.

Snider, J., Hill, R. P., and Martin, D. (2003), "Corporate Social Responsibility in the 21st Century: A View from the World's Most Successful Firms”, Journal of Business Ethics, Vol. 48, pp. 175-187.

Tixier, M. (2003), "Soft vs. Hard approach in communicating on CSR", Thunderbird International Business Review, Vol. 45 No. 1, pp. 71-91.

Tschopp, D. J. (2005), "Corporate Social Responsibility: A Comparison Between the United States and the European Union", Corporate Social Responsibility and Environmental Management, Vol. 12, pp. 55-59.

Turban D.B. and Greening D.W. (1996), "Corporate social performance and attractiveness to prospective employees", Academy of Management Journal, Vol. 40 No. 3, pp. 658-683.

Westhues, M. and Einwiller, S. (2006), "Corporate Foundations: Their Role for Corporate Social Responsibility communication”. Corporate Reputation Review, Vol. 9 No. 2, pp. 144-153.

Williams, S. M. and Pei, C. A. H. W. (1999), "Corporate Social Disclosures by Listed companies on Their Web Sites: An International Comparison", The International Journal of Accounting, Vol. 34 No. 3, pp. 389-419.

Zéghal, D. and Ahmed, S. A. (1990), “Comparison of Social Responsibility Information Disclosure Media used by Canadian Firms", Accounting, Auditing and Accountability Journal, Vol. 3 No. 1, pp. 38-53. 
${ }^{[1]}$ On this item, the questionnaire allowed only exclusive choices.

${ }^{[2]}$ Pearson Chi square .001. 